\section{Emergency endoscopic reduction of a gastric volvulus}
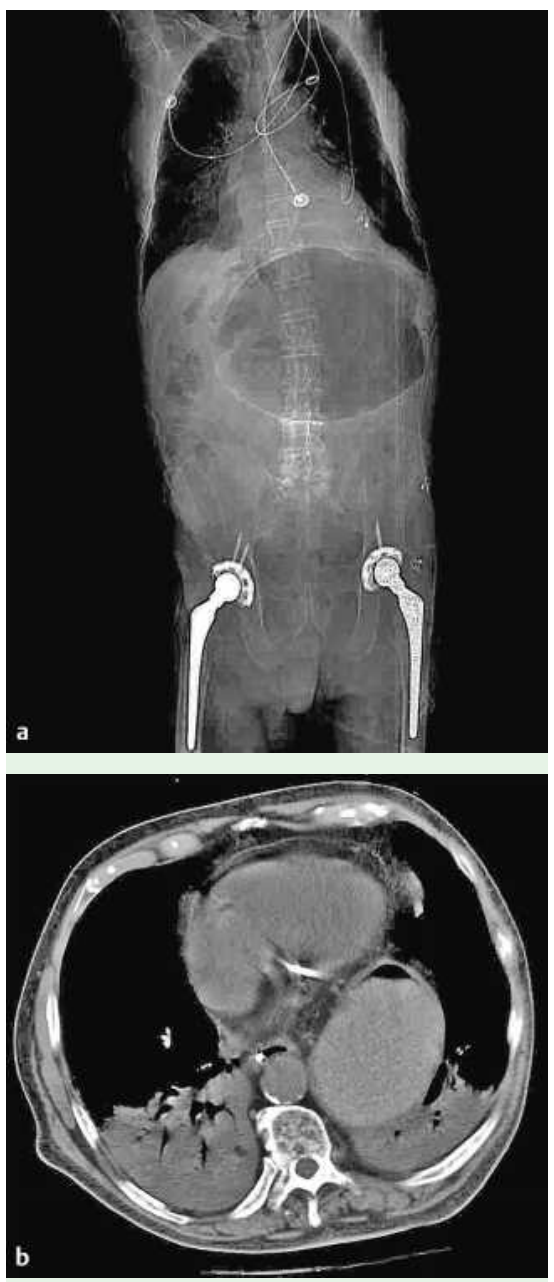

Figure 1 a Computed tomographic views showing gastric distension. $\mathbf{b}$ Part of the gastric body can be seen to be herniating into the thoracic cavity. Nissen fundoplication.
An 86-year-old man presented with a 3 day history of abdominal distension, epigastric pain, and vomiting. Computed tomography showed gastric distension, with part of the gastric body herniating into the thoracic cavity, and a paraesophageal hernia. These findings were consistent with a mesenteroaxial gastric volvulus ( $\bullet$ Figure 1 ). The patient was significantly dehydrated and further tests revealed that he had renal failure, metabolic acidosis, and cardiac arrhythmias. Immediate surgical intervention was considered to be an extremely high-risk option, so the volvulus was reduced endoscopically.

After insertion of the endoscope and gentle air insufflation, the volvulus was reduced, revealing erythematous mucosa with multiple ischemic-appearing ulcers throughout the gastric body ( $\bullet$ Figure 2 ). Reduction of the volvulus was confirmed by abdominal radiography, and the patient's hemodynamic status improved with supportive measures. One week after this endoscopic reduction the gastric volvulus recurred. However, the intervening week had allowed time for the patient to stabilize and he presented a lower surgical risk. He underwent successful reduction of the hernia, gastropexy, and a

Gastric volvulus is a rotation of the stomach that results in a closed-loop obstruction [1]. This can present with either acute or chronic symptoms, depending on the degree of obstruction [2]. In adults

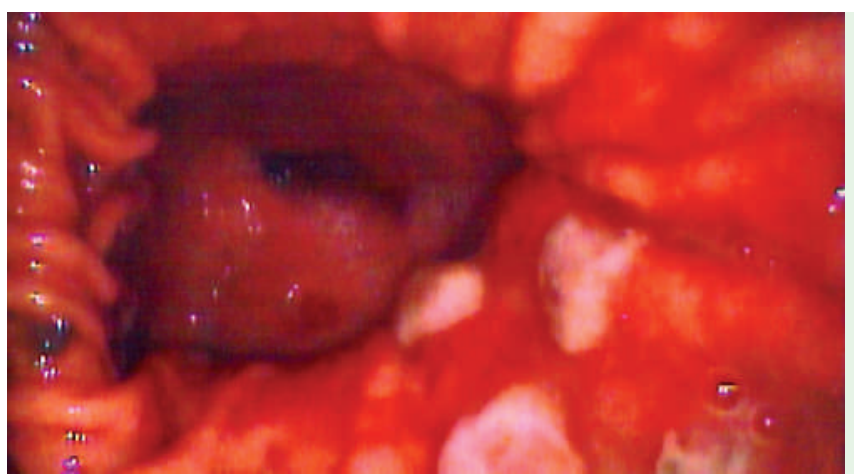

Figure 2 Endoscopic view of the gastric body, showing ischemic ulcers, after reduction of the gastric volvulus. it is usually associated with a paraesophageal hernia [3]. Gastric volvulus can be described according to its location relative to the diaphragm and its axis of rotation as either "organoaxial" or "mesenteroaxial" [4]. Without prompt treatment, the incidence of ischemic necrosis in an acute volvulus is significant, resulting in a mortality of $30 \%-50 \%$ [2]. Endoscopy in our patient demonstrated ischemic ulcers, emphasizing the severity of his presentation. The treatment of choice is surgical reduction, either open or laparoscopic [5]. However, in the emergency setting, the mortality associated with surgery can be high and endoscopic reduction should be considered to allow time for the patient to be adequately resuscitated.

\section{Endoscopy_UCTN_Code_TTT_1AO_2AN}

\section{K. Kulkarni, J. Nagler}

Division of Gastroenterology and

Hepatology, Weill Cornell Medical Center, New York, USA

\section{References}

1 Wolfgang R, Lee JG. Endoscopic treatment of acute gastric volvulus causing cardiac tampanode. J Clin Gastroenterol 2001; 32: 336 339

2 Shivanand G, Seema S, Srivastava DN et al. Gastric volvulus: acute and chronic presentation. Clin Imaging 2003; 27: 265-268

3 Gourgiotis S, Vougas V, Germanos S et al. Acute gastric volvulus: diagnosis and management over 10 years. Dig Surg 2006; 23: 169- 172

4 Godshall D, Mossallam U, Rosenbaum R. Gastric volvulus: case report and review of the literature. J Emerg Med 1999; 17: 837 - 840

5 Teague WJ, Ackroyd R, Watson DI et al. Changing patterns in the management of gastric volvulus over 14 years. Br J Surg 2000; 87: $358-361$

\section{Bibliography}

DOI 10.1055/s-2007-966584

Endoscopy 2007; 39: E173

(c) Georg Thieme Verlag KG Stuttgart · New York . ISSN 0013-726X

\section{Corresponding author}

\section{J. Nagler, MD}

407 East 70th Street

New York

New York 10021

USA

Fax: +1-212-517-6625

jnagler407@aol.com 